\title{
Relative index of ankle muscle activations on agonistic phase between subjects with and without flat foot
}

\author{
Paul S. Sung \\ Department of Physical Therapy, Human Motion Laboratory, University of Scranton, United States. \\ Correspondence: Paul S. Sung, PhD. Address: Department of Physical Therapy, Panuska College of Professional Studies, \\ University of Scranton, 800 Linden St, Scranton, PA 18510, United States. Email: drpsung@gmail.com
}

Received: August 27, 2015

Accepted: October 7, $2015 \quad$ Online Published: November 2, 2015

DOI : $10.5430 /$ jbei.v2n1p129

URL: http://dx.doi.org/10.5430/jbei.v2n1p129

\section{Abstract}

Background: Although co-activation of ankle muscles has been reported, relative ankle muscle activation in subjects with flat foot has not been carefully investigated. The aim of this study was to compare the relative activation index (RAI) on the tibialis anterior (TA) and medial gastrocnemius (GTN) muscles during active ankle range of motion (ROM) between subjects with and without flat foot.

Methods: There were 17 subjects with flat foot and 17 age- and gender-matched control subjects who participated in this study. The RAI based on electromyography (EMG) was measured during the agonist phase at a controlled velocity of ankle motion $\left(10^{\circ}\right.$ second). The subject was seated upright with the tested foot held firmly onto a footplate that was attached to a torque sensor. The ankle being measured was strapped to the leg support of the Intel stretch device at $60^{\circ}$ of knee flexion. The RAI was analyzed by the summation of EMG activity from the agonistic time window divided by the total EMG activity during full active ankle ROM.

Results: The RAI was significantly different on the TA muscle ( $t=3.08, P=0.004$ ), but no difference was found on the GTN muscle $(t=-1.24, P=0.23)$ in subjects with flat foot. There was an interaction between group and RAI (F =7.89, $P=0.007)$; however, the RAI demonstrated no interaction with age $(\mathrm{F}=2.59, P=0.14)$, height $(\mathrm{F}=3.73, P=0.06)$, or weight $(\mathrm{F}=2.96, P=0.09)$.

Conclusions: The RAI indicated a lack of TA muscle activation in the flat foot group. Such dissociated activation in the flat foot group might be relevant to the inefficiency of synergistic motions. The relative activation of the agonistic phase needs to be further investigated to compare co-activation of synergistic muscle activation with various functional tasks.

\section{Key words}

Torque, Angle, Ankle muscle, Flat foot, Relative activation index

\section{Introduction}

Ankle muscle stiffness is a common musculoskeletal dysfunction with proprioceptive deficits which are related to joint stability ${ }^{[1,2]}$. The stiffness is generally defined as the ratio of moment to angular deflection of the specific joint ${ }^{[3,4]}$ as 
quantified by the slope of the length-tension relationship ${ }^{[5]}$. This stiffness dominates the mechanical behavior of the ankle muscles, contributes to the risk of falls, and impairs standing balance in daily activities ${ }^{[6]}$.

The primary mechanism for lower limb mobility might be affected by ankle stiffness, which is more important than that of knee and hip stiffness ${ }^{[7,8]}$. Ankle stiffness has been attributed to the functional consequences of abnormal kinematics, kinetics, and altered muscle activation ${ }^{[9-11]}$. Electromyography (EMG) activity has found that ankle stiffness is related to reduced dynamic mobility capacity as well as decreased strength and proprioception ${ }^{[1,12,13]}$. Although the magnitude of ankle motion is influenced by joint congruence and ligament elasticity ${ }^{[14,15]}$, there is limited investigation on ankle active range of motion (ROM), especially in subjects with flat foot.

Radiographic investigations are the reference standard to determine the magnitude of flat foot; however, they fail to quantify imbalance of ankle motion or to serve as an objective assessment of flat foot ${ }^{[16-18]}$. Flat foot deformity is a depression of the medial longitudinal foot arch, which can lead to overuse of the lower limbs, injury, and foot dysfunction as confirmed by the navicular drop test ${ }^{[19,20]}$. Flat foot deformity contributes to musculoskeletal injury via altered motion of the lower extremity ${ }^{[19]}$. The relationship between foot mobility and lower limb motion was reported, and flat foot could be recognized as a risk factor for postural stability ${ }^{[21-23]}$. These previous studies investigated the quantified assessment of mobility and validated flat foot assessment procedures. However, those studies were not clear whether the ankle muscles are activated synchronously to modulate joint impedance or sequentially to perform distinct biomechanical functions. In addition, most studies were not conclusive due to heterogeneity between studies, small effect size with the risk of bias, and, more importantly, lack of an objective measure ${ }^{[2,21,24]}$.

Although there is limited investigation of flat foot and ankle muscle activation, a loss of functional integrity may affect ankle muscle stiffness in subjects with flat foot. The altered muscle co-activation could be from diminished peripheral perception, delayed spinal reflex-loop recruitment, or higher muscle activity levels with increased co-activation and decreased spinal reflex transmission ${ }^{[1,12,21]}$. However, a relative activation index (RAI) on the tibialis anterior (TA) and medial gastrocnemius (GTN) muscles was not previously investigated to quantify specific phases of active ankle ROM. A quantified RAI might differentiate the agonistic phase during dorsiflexion (DF) and plantar flexion (PF) in subjects with and without flat foot.

It is generally accepted that increasing the flexibility of the ankle joint promotes better performance and decreases the number of injuries ${ }^{[25-28]}$; however, contradictory findings were reported in the literature ${ }^{[29-31]}$. The dissociated activation in the ankle muscles is critical for the control of the co-activated muscle pattern by the RAI. More importantly, there is limited clinical investigation on agonist responses during ankle motion in subjects with and without flat foot. The RAI might be related to individual characteristics, including age, height, and weight. Such differences have the potential to contribute to variations in the co-activation of the ankle muscles in older adults with flat foot.

Therefore, the aim of this study was to compare the RAI on the TA and GTN ankle muscles during specific phases of DF and PF while considering demographic factors between subjects with and without flat foot. The hypothesis of this study was that there would be a different RAI on the agonistic phase during ankle ROM between subjects with and without flat foot.

\section{Methods}

\subsection{Participants}

Participants with flat foot were recruited from the University community by advertisement. Individuals were eligible to participate in the study if they: 1 ) measured $>9 \mathrm{~mm}$ on the navicular drop test, 2) were 30 years of age or older, 3 ) were not 
diagnosed with any lower extremity injuries, and 4) had no acute pain or dysfunction surrounding the ankle or foot at the time of the study.

Individuals were excluded from participation if they: 1) reported continuous pain or underwent surgery on a lower extremity within the past 2 months, 2) had a diagnosed psychological illness that might interfere with the study protocol, 3) had experienced overt neurological signs (sensory deficits or motor paralysis), 4) had active medical, surgical, or neurologic illness, painful conditions, history of peripheral neuropathies, or any disorders affecting the central nervous system, or 5) were pregnant.

Subjects were withdrawn from the study if they requested to withdraw. The control group was recruited based on similar individual characteristics as the subjects with flat foot. Those subjects who met study inclusion criteria received information regarding the study and signed a copy of the Institutional Review Board approved consent form.

\subsection{Experimental setup}

Each participant's subtalar joint was measured for the navicular height. The distance between the tubercle of the navicular bone was measured in sitting (non-weight bearing position) as well as in standing (full-weight bearing position). The normal range of navicular drop was defined between 5 and $9 \mathrm{~mm}$ from the navicular drop test ${ }^{[23]}$. Therefore, participants with a navicular drop exceeding $9 \mathrm{~mm}$ were included in the flat foot group. For reliability in our study, the intra class correlations were calculated to determine navicular drop. The intra class correlation coefficients were used to determine the degree of test-retest reliability, ranged from 0.85 to 0.93 , and were interpreted as excellent ${ }^{\text {[32] }}$.

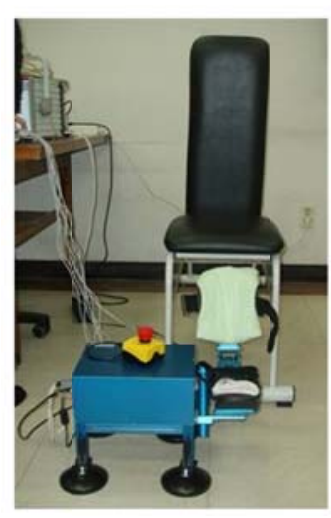

A

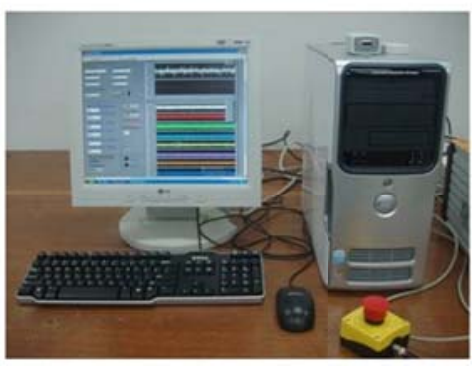

B

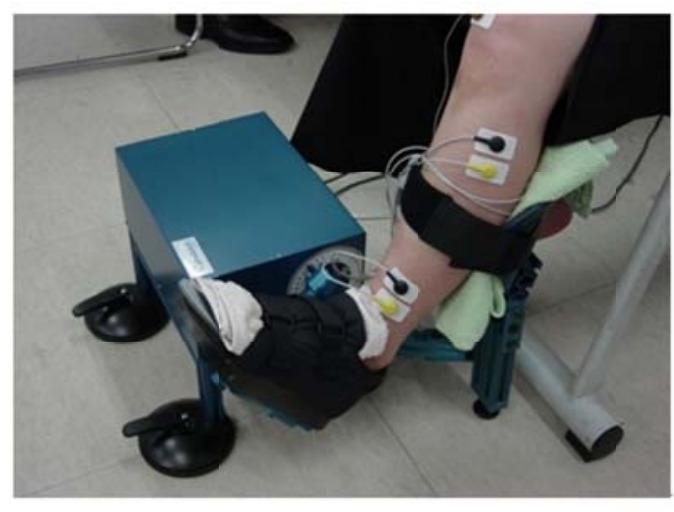

C

Figure 1. The experimental setup for ankle stiffness measurements. A): The device was fixed to the chair to prevent movement relative to the subject. The seat was adjusted to align the ankle flexion axis at a selected knee flexion ROM. The foot of the subject was fixed on the footplate, and the lower leg was fixed to a leg support. B): A LabVIEW program was designed to control the data-acquisition device and to obtain the data. C): A six-axis force sensor was mounted between the motor shaft and the foot attachment. The surface EMG electrodes were placed over the GTN and TA muscles.

The outcome evaluation included EMG analysis using the Intel stretch device (Rehabtek, IL, USA). The reliability of this device was previously reported ${ }^{[5]}$. As shown in Figure 1, this study investigated ankle muscle activation patterns during agonist and antagonist phases of ankle movement. The subject was seated upright on the chair with the tested foot held firmly onto a footplate that was attached to a torque sensor. The lower extremity being measured was strapped to the leg support at $60^{\circ}$ of knee flexion. The thigh and trunk were strapped to the seat and backrest, respectively, with the seat and leg support adjusted to a comfortable position for the knee and hip joints at $60^{\circ}$ and $85^{\circ}$ of flexion, respectively. The participant actively moved the ankle joint at a consistent velocity of $10^{\circ}$ /second. 
Figure 1 indicates the experimental setup for ankle stiffness measurements. The device was fixed to the chair to prevent movement relative to the subject, and a LabVIEW program was designed to control the data-acquisition device and to obtain the data. The aluminum footplate, lined with rubber pads, supported the whole length of the sole and the medial side of the foot. A molded clamping device with a firm cushioning pad pressed the dorsum of the foot onto the footplate. The ankle joint was fixed to permit active and passive ROM at the neutral position. This position minimized contributions of the passive and intrinsic components associated with ankle joint movement. The position of the footplate was also adjusted to align the ankle flexion axis with the axis of the torque sensor. The footplate was mounted onto the motor shaft through a 6-axis force sensor that measured the torques at the ankle joint. The ankle joint was moved actively in DF and PF directions, and the motion was monitored digitally by position/velocity and torque.

The electrode sites on each participant were shaved, and rubbing alcohol was used to reduce skin impedance. The electrodes were placed on the muscle belly about $1 / 3$ of the distance from the insertion of the individual muscles and oriented parallel to the direction of the tested muscle fibers ${ }^{[32]}$. A reference electrode was placed on the patella. The EMG data were collected using Noraxon Telemyo (Noraxon Inc., Scottsdale, AZ, USA), and surface EMG electrodes were placed over the GTN and TA muscles. The EMG signals were amplified, band-pass filtered $(10 \mathrm{~Hz}, 450 \mathrm{~Hz})$, and notch filtered $(60 \mathrm{~Hz}, 120 \mathrm{~Hz}$ ) before being digitally recorded at $1000 \mathrm{~Hz}$ and processed into the root mean square.

\subsection{Data reduction}

As Figure 2 indicates, 14 cycles of DF and PF were performed during the 120 sec recording time. Surface EMG data recorded from the GTN and TA muscles, and each cycle was identified by the peak point of the angle channel (see Figure 2A) and averaged throughout all cycles (see Figure 2B). Based on the angle of the ankle and the surface EMG pattern of the GTN, PF started at $10 \%$ and ended at $60 \%$ of the cycle, while DF started at $60 \%$ and ended at $10 \%$ of the successive cycle (see Figure 2B). Therefore, most of the surface EMG power of the GTN was expected during the PF phase, while the TA muscle was expected to be active during the DF phase.
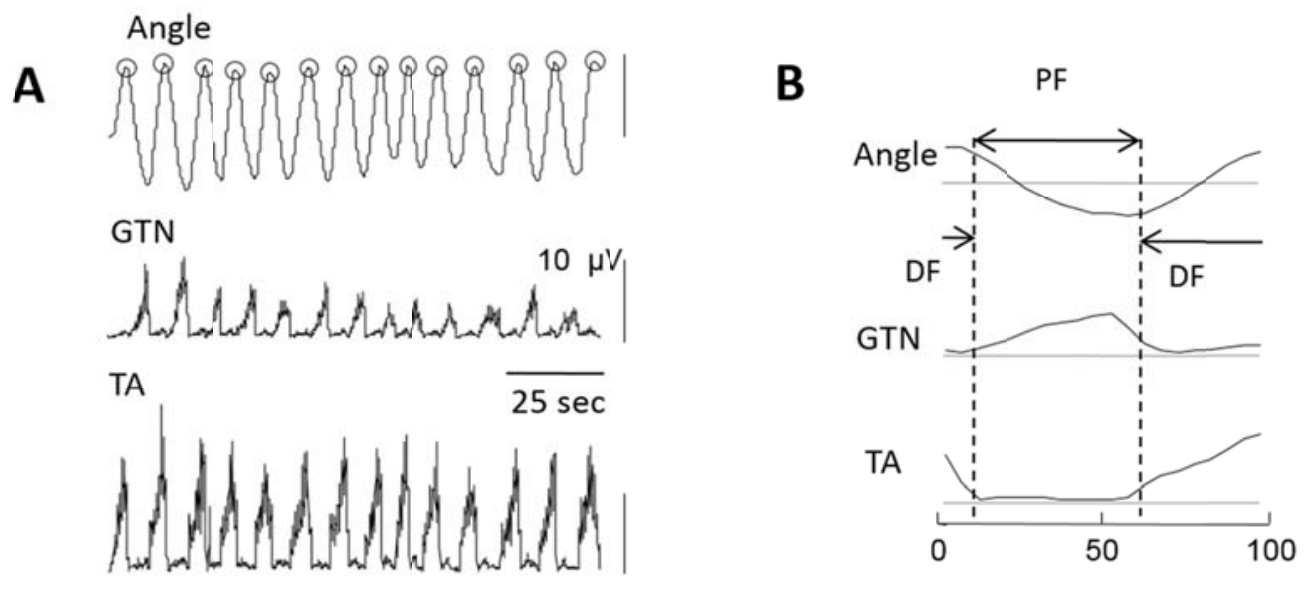

Figure 2. Recorded signals and phase identification process. A): The angle and surface EMG data from GTN and TA muscles. The starting point of each cycle was identified and is shown by a circle. The GTN muscle was active during PF, and the TA muscle was active during DF. B): All identified cycles were averaged. PF was identified by the angle of the ankle (10\%-60\% of cycle), and DF was identified for the rest of the cycle ( $0 \%-10 \%$ and $60 \%-100 \%)$.

In order to quantify the relative activation of a muscle on the agonistic phase, the summation of the muscle activity based on surface EMG from the agonistic time window was divided by the total surface EMG during the cycle. For example, the activity of GTN from $10 \%$ to $60 \%$ over total GTN was computed as GTN relative activation of a muscle on the agonistic 
phase. The activity of TA from $60 \%$ to $10 \%$ of the successive cycle was computed as TA relative activation of a muscle on the agonistic phase.

Three examples are shown in Figure 3 to describe the sensitivity of the relative activation of a muscle on the agonistic phase. The first subject (see Figure 3A) had isolated the GTN in PF (dotted box) and isolated the TA in DF. Both muscles had high relative activation of a muscle on the agonistic phase $(>0.7)$, which indicates that they were not used as antagonists during opposite movements. The second subject (see Figure 3B) had good isolated activity in PF (GTN index $=0.65$ ), while the TA muscle was also activated in PF as well as DF, which resulted in low TA relative activation of a muscle on the agonistic phase (0.54). The third subject (see Figure 3C) activated the TA more in PF than in DF, which resulted in low TA RAI during PF (0.35).

Our previous study indicated that the reliability ICC $_{2,1}$ coefficient of ankle stiffness between-day for both examiners was 0.77 for the right ankle and 0.76 for the left ankle with a 0.05 standard error of measurement for ankle stiffness for the right side and 0.04 for the left side. The ICC values of the two examiners were also high ( 0.87 and 0.86 ) based on Chronbach's alpha ${ }^{[5]}$.

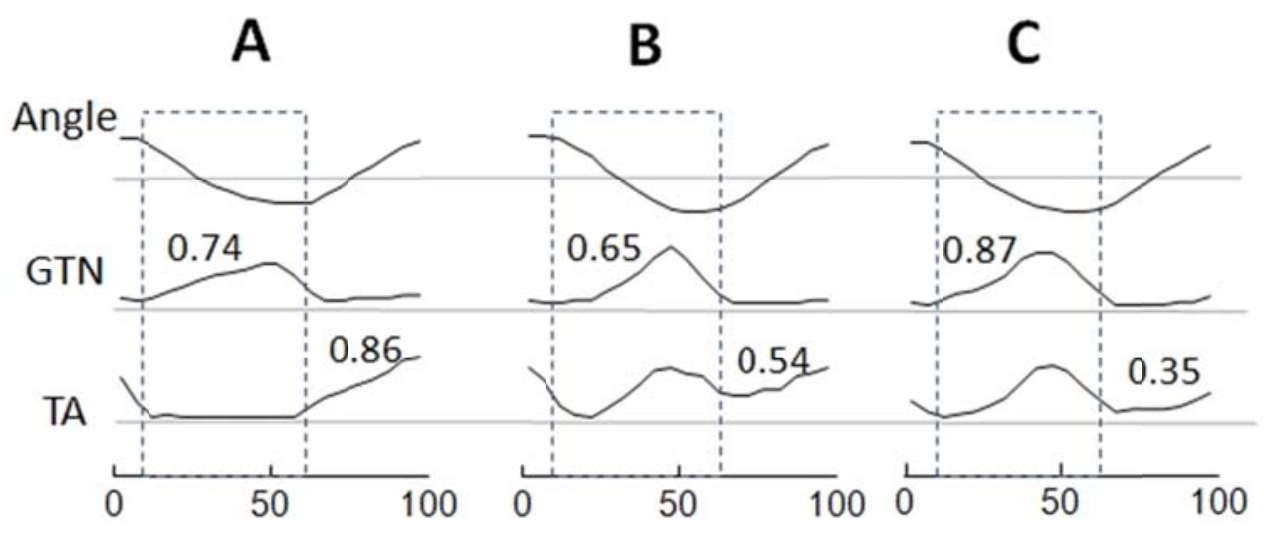

Figure 3. An example of the RAI of agonist muscle performance for three individual subjects. A): GTN was active during $\mathrm{PF}$ (dotted box), and the relative ankle index value was 0.74 . The TA was selectively active during $\mathrm{DF}$, and the relative ankle index was 0.86 . B): This subject had relatively good activation of GTN during PF, but TA was also active during PF. Therefore, the relative ankle index was 0.54 for TA. C): This subject had high activation of TA during PF of which activation was higher than DF.

\subsection{Statistical analysis}

Statistical analyses were completed using SPSS 22 (SPSS, Chicago, IL). An independent $t$-test was used to analyze dependent variables based on group. A mixed repeated measure analysis of variance (ANOVA) was used between groups for each dependent variable. For all statistical tests, type I error rate was set at 0.05 .

\section{Results}

The subject demographics are summarized in Table 1. Seventeen control subjects and 17 subjects with flat foot enrolled in the study. The ages of the subjects ranged from 33 to 74 years, and there was no significant difference between groups ( $t=-0.94, P=0.35)$. There were no differences on height $(t=1.42, P=0.16)$, weight $(t=0.21, P=0.83)$, foot length ( $t=1.91, P=0.06)$, or foot width $(t=1.35, P=0.18)$. However, the navicular drop test indicated a significant difference between groups $(t=24.48, P=0.01)$. 
Table 1. Summary of participants’ demographics and groups with selected demographics

\begin{tabular}{|c|c|c|c|c|}
\hline Variable & Control group & Flat foot group & $t$ & $\boldsymbol{P}$ \\
\hline Number of participants & 17 & 17 & & \\
\hline \multicolumn{5}{|l|}{ Age (years) } \\
\hline Range & $34-62$ & 33-74 & -0.94 & 0.35 \\
\hline Mean \pm SD & $43.65 \pm 10.85$ & $47.71 \pm 14.01$ & & \\
\hline \multicolumn{5}{|l|}{ Height (cm) } \\
\hline Range & $155-174$ & $141-180$ & 1.42 & 0.16 \\
\hline Mean \pm SD & $163.24 \pm 4.88$ & $158.88 \pm 11.58$ & & \\
\hline \multicolumn{5}{|l|}{ Weight (kg) } \\
\hline Range & $48-82$ & $45-93$ & 0.21 & 0.83 \\
\hline Mean \pm SD & $65.06 \pm 10.58$ & $64.01 \pm 16.21$ & & \\
\hline \multicolumn{5}{|l|}{ Foot length (cm) } \\
\hline Range & $22-28$ & $21-27$ & 1.91 & 0.06 \\
\hline Mean \pm SD & $24.96 \pm 1.94$ & $23.76 \pm 1.68$ & & \\
\hline \multicolumn{5}{|l|}{ Foot width (cm) } \\
\hline Range & $8-11$ & $9-12$ & 1.35 & 0.18 \\
\hline Mean \pm SD & $10.10 \pm 0.89$ & $9.66 \pm 0.81$ & & \\
\hline \multicolumn{5}{|l|}{ ND (mm) } \\
\hline Range & $5.3-8.2$ & $11.2-14.4$ & 24.48 & $0.01 *$ \\
\hline Mean \pm SD & $6.47 \pm 0.79$ & $12.23 \pm 0.76$ & & \\
\hline
\end{tabular}

Note. SD: standard deviation, ND: navicular drop, ${ }^{*} P<0.05$.

The relative activation of each muscle on the agonistic phase during ankle ROM was quantified during movement in the device, and the RAI of each muscle was compared between subjects with and without flat foot. As shown in Figure 4, the RAI was significantly different on the TA muscle $(0.70 \pm 0.09$ for control group vs. $0.54 \pm 0.19$ for flat foot group; $t=3.08, P=0.004)$, but there was no difference on the GTN muscle $(0.74 \pm 0.09$ for control group vs. $0.77 \pm 0.07$ for flat foot group, $t=-1.24, P=0.23$ ), in subjects with flat foot. The mixed repeated measure ANOVA indicated that there was an interaction between group and RAI ( $F=7.89, P=0.007)$. However, the RAI demonstrated no interactions with age ( $\mathrm{F}=2.59, P=0.14)$, height $(\mathrm{F}=3.73, P=0.06)$, or weight $(\mathrm{F}=2.96, P=0.09)$.

\section{Discussions}

The purpose of this study was to compare the RAI on the TA and GTN ankle muscles during the agonistic phase of ankle motion between subjects with and without flat foot. The hypothesis of this study was that there would be a different RAI for the agonistic phase during ankle ROM between subjects with and without flat foot. The results of this study indicated that the RAI significantly decreased on the TA muscle in subjects with flat foot. There was an interaction between group and RAI; however, the demographic factors, such as age, height, and weight, demonstrated no interaction with RAI.

In order to activate the ankle muscles by the TA at a constant velocity $(10 \%$ second), proper co-activation of the antagonistic muscles (GTN) is also required. The relative activation of a muscle on the agonistic phase of the TA decreased below 0.5, which indicated that the TA muscle was more active during PF than DF. These results provided evidence that PF requires a certain level of antagonist co-activation possibly due to the lack of coordinated GTN muscle recruitment in the flat foot group. 


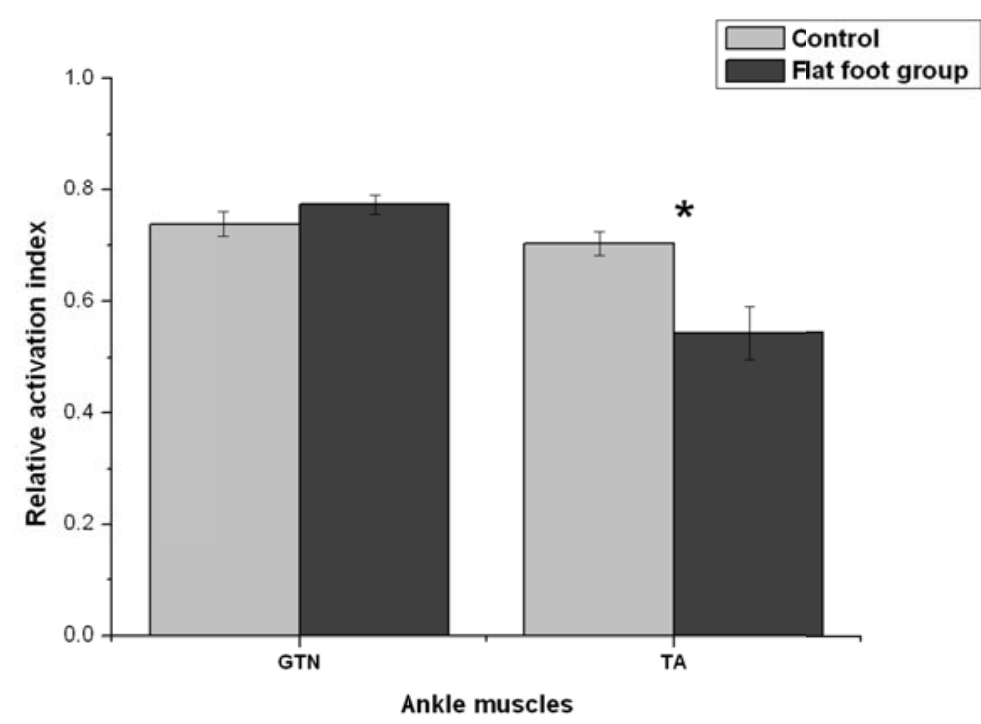

Figure 4. The group difference of RAI for ankle muscles. There were significant differences on the TA muscle $(t=3.08$, $P=0.004)$, but there were no differences on the GTN muscle $(t=-1.24, P=0.23)$. There was an interaction between group and RAI $(\mathrm{F}=7.89, P=0.007)$.

The primary cause for the development of flat foot deformity is posterior tibialis tendon dysfunction ${ }^{[19]}$. The tibialis posterior is located in the deep posterior compartment of the leg. Without the tibialis posterior, the other ligaments and joint capsules gradually become weak. Thus flatfoot develops; and, therefore, gait and balance are seriously affected. Although the posterior tibialis muscle plays a key role during gait, this muscle activation can be measured by either needle insertion or ultrasonography ${ }^{[34]}$. The RAI on the GTN muscle by surface EMG indicated a synergistic action to maintain the medial longitudinal arch of the foot. The insufficient support of the medial longitudinal arch from flat foot deformity could disrupt the function of the TA muscle.

The imbalance of ankle muscles could be caused by relative muscle activation, especially task-specific co-activation of the muscles as well as a high level of specificity in their function. The RAI might be useful to apply for cyclic maneuvers, such as joint movement, since the relative activation on the agonistic phase is sensitive to detect co-activation of corresponding muscles. In addition, the relative activation of the agonist phase provides further insight into the mechanism underlying dissociated activations in synergistic ankle movement. Since most dysfunctions develop into imbalances of muscle activation, the selective activation of the ankle muscles needs to be adjusted during movement in each phase of ankle motion.

It was also reported that excessive pronation, which was determined by navicular drop, was attributed to a decrease in PF strength and generates less torque ${ }^{[35]}$. Since excessive pronation affects the timing and magnitude of extrinsic muscle activity, subjects with flat foot lack coordinated ankle motion. Further studies are required to investigate the roles of the various ankle muscles in subjects with flat foot during active ankle ROM. It is important to monitor co-activation following specific interventions based on the RAI by evaluating subjects with flat foot. This index would suggest that the agonistic phase of the GTN muscle might be altered in subjects with flat foot as a result of navicular drop.

The distribution of relative activation of the ankle muscles on the agonistic phase for the TA was relatively higher than the GTN muscle, which implies that the TA muscle was selectively activated during DF in the control group. Previous studies suggested that young adults and seniors use different ankle strategies to adjust their balance due to altered antagonist muscle co-activation as seniors demonstrated higher TA contributions during single limb standing ${ }^{[36,37]}$. However, the 
results of our study demonstrated no interaction with RAI for aging, body weight, or height even though our previous study indicated that gender and body weight were critical factors for ankle stiffness ${ }^{[5]}$.

Although our study was performed in a laboratory environment, the RAI during the agonist phase needs to be compared with the antagonist phase for specific ankle muscle activations to quantify the index for subjects with and without flat foot. The relative activation of a muscle on the agonistic phase was sensitive to detect co-activation of corresponding muscles during the antagonistic phase. It is important for the ankle muscles to be flexible in order to have better coordinated performance during ankle movement.

However, the underlying mechanisms that determine the activation levels of individual muscles are not well understood in individuals with flat foot. A mechanism underlying the dissociated activations in specific phases of the ankle muscles needs to be investigated for specific muscle control to specific motor tasks. The co-activation of the TA between DF and PF can be observed during ambulation in a phase-dependent manner. Therefore, a relative index for the ankle movement on the agonistic phase might be important to apply co-activation patterns during functional activities, especially for those subjects with lower limb dysfunctions.

There were several limitations to the current study. One limitation was the ages of the participants (which ranged from 33 to 74 years in the flat foot group) who comprised a small sample size. This age variation as well as anatomic variations among individuals might invalidate the results; however, subgroup analyses would provide more accurate results of intra/inter-variability for future studies. Even though our study did not include subjects who possess altered mechanical changes with possible proprioceptive disruption, increasing the number of subjects would serve to increase the power of the study as well.

Second, our study examined only static sitting posture, which could affect ankle stiffness less than a dynamic condition. In this position, the GTN muscle might be affected, which is influenced by other structures. As a consequence, the measurements of relative ankle muscle activation for the agonist phase may differ significantly compared with other studies. However, our study investigated mainly relative ankle muscle activation, especially during the agonist phase, to compare subjects with and without flat foot. These findings suggest that further investigations are needed which focus on the functional characteristics of specific tasks that develop and/or maintain ankle muscle activation.

\section{Conclusions}

The results of this study indicated that the RAI was significantly different on the TA muscle, but no difference on the GTN muscle in subjects with flat foot was found. The ability to accurately quantify the agonistic phase of muscle activation and factors that influence it has been poorly understood. Although no muscle activation onset time was measured in our study, the flat foot group demonstrated relatively dissociated activation on the TA during DF. Future studies should include a larger sample size with further investigation of synergistic ankle muscle activation during various activities in subjects with flat foot.

\section{Acknowledgements}

This work was supported by Panuska College of Professional Studies at the University of Scranton, Pennsylvania.

\section{Conflict of interest statement}

None of the authors has any financial or personal conflicts of interest in relation to the submission, other people, or any organizations. 


\section{References}

[1] Docherty CL, Arnold BL, Zinder SM, et al. Relationship between two proprioceptive measures and stiffness at the ankle. J Electromyogr Kinesiol. 2004; 14: 317-24. http://dx.doi.org/10.1016/S1050-6411(03)00035-X

[2] Lohrer H, Nauck T, Gehring D, et al. Differences between mechanically stable and unstable chronic ankle instability subgroups when examined by arthrometer and FAAM-G. J Orthop Surg Res. 2015; 10: 32. PMid:25890204.

http://dx.doi.org/10.1186/s13018-015-0171-2

[3] Maquirriain J, Kokalj A. Acute Achilles tendinopathy: effect of pain control on leg stiffness. J Musculoskelet Neuronal Interact. 2014; 14: 131-6. PMid:24583548.

[4] Palmer TB, Akehi K, Thiele RM, et al. Dorsiflexion, Plantar-Flexion, and Neutral Ankle Positions During Passive Resistance Assessments of the Posterior Hip and Thigh Muscles. J Athl Train. 2015; 50: 467-74. PMid:25658906. http://dx.doi.org/10.4085/1062-6050-49.6.04

[5] Sung PS, Baek JY, Kim YH. Reliability of the intelligent stretching device for ankle stiffness measurements in healthy individuals. Foot (Edinb). 2010; 20: 126-32. PMid:20951025. http://dx.doi.org/10.1016/j.foot.2010.09.005

[6] Loram ID, Lakie M. Direct measurement of human ankle stiffness during quiet standing: the intrinsic mechanical stiffness is insufficient for stability. J Physiol. 2002; 545: 1041-53. http://dx.doi.org/10.1113/jphysiol.2002.025049

[7] Farley CT, Morgenroth DC. Leg stiffness primarily depends on ankle stiffness during human hopping. J Biomech. 1999; 32: 267-73. http://dx.doi.org/10.1016/S0021-9290(98)00170-5

[8] Hobara H, Inoue K, Omuro K, et al. Determinant of leg stiffness during hopping is frequency-dependent. Eur J Appl Physiol. 2011; 111: 2195-201. PMid:21318314. http://dx.doi.org/10.1007/s00421-011-1853-z

[9] Ross M. Use of the tissue stress model as a paradigm for developing an examination and management plan for a patient with plantar fasciitis. J Am Podiatr Med Assoc. 2002; 92: 499-506. PMid:12381799. http://dx.doi.org/10.7547/87507315-92-9-499

[10] Dananberg HJ. Sagittal plane biomechanics. American Diabetes Association. J Am Podiatr Med Assoc. 2000 ; 90: 47-50. PMid:10659532. http://dx.doi.org/10.7547/87507315-90-1-47

[11] Banwell HA, Mackintosh S, Thewlis D, et al. Consensus-based recommendations of Australian podiatrists for the prescription of foot orthoses for symptomatic flexible pes planus in adults. J Foot Ankle Res. 2015; 7: 49. PMid:25558287. http://dx.doi.org/10.1186/s13047-014-0049-2

[12] Ng TK, Lo SK, Cheing GL. The association between physical characteristics of the ankle joint and the mobility performance in elderly people with type 2 diabetes mellitus. Arch Gerontol Geriatr. 2014; 59: 346-52. PMid:25064030. http://dx.doi.org/10.1016/j.archger.2014.07.001

[13] Chung SG, van Rey E, Bai Z, et al. Separate quantification of reflex and nonreflex components of spastic hypertonia in chronic hemiparesis. Arch Phys Med Rehabil. 2008; 89: 700-10. PMid:18374001. http://dx.doi.org/10.1016/j.apmr.2007.09.051

[14] Zhao H, Ren Y, Roth EJ, et al. Concurrent deficits of soleus and gastrocnemius muscle fascicles and Achilles tendon post stroke. J Appl Physiol (1985). 2015; 118: 863-71. PMid:25663670. http://dx.doi.org/10.1152/japplphysiol.00226.2014

[15] Zhang L, Chung S, Bai Z, et al. Intelligent stretching of ankle joints with contracture/spasticity. IEEE Trans Neural Syst Rehabil Eng. 2002; 10: 149-57. PMid:12503779. http://dx.doi.org/10.1109/TNSRE.2002.802857

[16] Evans AM, Copper AW, Scharfbillig RW, et al. Reliability of the foot posture index and traditional measures of foot position. J Am Podiatr Med Assoc. 2003; 93: 203-13. PMid:12756311. http://dx.doi.org/10.7547/87507315-93-3-203

[17] McPoil TG, Cornwall MW, Vicenzino B, et al. Effect of using truncated versus total foot length to calculate the arch height ratio. Foot (Edinb). 2008; 18: 220-7. PMid:20307441. http://dx.doi.org/10.1016/j.foot.2008.06.002

[18] Scharfbillig R, Evans AM, Copper AW, et al. Criterion validation of four criteria of the foot posture index. J Am Podiatr Med Assoc. 2004; 94: 31-8. PMid:14729988. http://dx.doi.org/10.7547/87507315-94-1-31

[19] Kohls-Gatzoulis J, Angel JC, Singh D, et al. Tibialis posterior dysfunction: a common and treatable cause of adult acquired flatfoot. Bmj. 2004; 329: 1328-33. PMid:15576744 . http://dx.doi.org/10.1136/bmj.329.7478.1328

[20] Levinger P, Murley GS, Barton CJ, et al. A comparison of foot kinematics in people with normal- and flat-arched feet using the Oxford Foot Model. Gait Posture. 2010; 32: 519-23. PMid:20696579. http://dx.doi.org/10.1016/j.gaitpost.2010.07.013

[21] Buldt AK, Murley GS, Butterworth P, et al. The relationship between foot posture and lower limb kinematics during walking: A systematic review. Gait Posture. 2013; 38: 363-72. PMid:23391750. http://dx.doi.org/10.1016/j.gaitpost.2013.01.010

[22] Wikstrom EA, Tillman MD, Smith AN, et al. A new force-plate technology measure of dynamic postural stability: the dynamic postural stability index. J Athl Train. 2005; 40: 305-9. PMid:16404452.

[23] Cote KP, Brunet ME, Gansneder BM, et al. Effects of Pronated and Supinated Foot Postures on Static and Dynamic Postural Stability. J Athl Train. 2005; 40: 41-6. PMid:15902323. 
[24] Evans AM, Rome K. A Cochrane review of the evidence for non-surgical interventions for flexible pediatric flat feet. Eur J Phys Rehabil Med. 2011; 47: 69-89. PMid:21448121.

[25] Bell DR, Padua DA, Clark MA. Muscle strength and flexibility characteristics of people displaying excessive medial knee displacement. Arch Phys Med Rehabil. 2008; 89: 1323-8. PMid:18586134. http://dx.doi.org/10.1016/j.apmr.2007.11.048

[26] Lephart SM, Pincivero DM, Giraldo JL, et al. The role of proprioception in the management and rehabilitation of athletic injuries. Am J Sports Med. 1997; 25: 130-7. PMid:9006708. http://dx.doi.org/10.1177/036354659702500126

[27] Mueller MJ, Minor SD, Schaaf JA, et al. Relationship of plantar-flexor peak torque and dorsiflexion range of motion to kinetic variables during walking. Phys Ther. 1995; 75: 684-93. PMid:7644572.

[28] Weiss PL, Hunter IW, Kearney RE. Human ankle joint stiffness over the full range of muscle activation levels. J Biomech. 1988; 21: 539-44. http://dx.doi.org/10.1016/0021-9290(88)90217-5

[29] Witvrouw E, Mahieu N, Danneels L, et al. Stretching and injury prevention: an obscure relationship. Sports Med. 2004 ; 34: $443-9$. PMid:15233597. http://dx.doi.org/10.2165/00007256-200434070-00003

[30] Lord SR, Caplan GA, Ward JA. Balance, reaction time, and muscle strength in exercising and nonexercising older women: a pilot study. Arch Phys Med Rehabil. 1993; 74: 837-9. http://dx.doi.org/10.1016/0003-9993(93)90010-8

[31] Gillespie LD, Gillespie WJ, Robertson MC, et al. Interventions for preventing falls in elderly people. Cochrane Database Syst Rev. 2003: CD000340. http://dx.doi.org/10.1002/14651858.cd000340

[32] Shrout PE, Fleiss JL. Intraclass correlations: uses in assessing rater reliability. Psychol Bull. 1979; 86: 420-8. http://dx.doi.org/10.1037/0033-2909.86.2.420

[33] Mademli L, Arampatzis A, Morey-Klapsing G, et al. Effect of ankle joint position and electrode placement on the estimation of the antagonistic moment during maximal plantarflexion. J Electromyogr Kinesiol. 2004; 14: 591-7. PMid:15301777. http://dx.doi.org/10.1016/j.jelekin.2004.03.006

[34] Won SJ, Yoon JS. Approach for needle insertion into the tibialis posterior: An ultrasonography study. Muscle Nerve. 2015. http://dx.doi.org/10.1002/mus.24794

[35] Snook AG. The relationship between excessive pronation as measured by navicular drop and isokinetic strength of the ankle musculature. Foot Ankle Int. 2001; 22: 234-40. PMid:11310866.

[36] Granacher U, Gruber M, Forderer D, et al. Effects of ankle fatigue on functional reflex activity during gait perturbations in young and elderly men. Gait Posture. 2010; 32: 107-12. PMid:20434345. http://dx.doi.org/10.1016/j.gaitpost.2010.03.016

[37] Lindemann U, Moe-Nilssen R, Nicolai SE, et al. Assessment of balance in unsupported standing with elderly inpatients by force plate and accelerometers. Aging Clin Expe Res. 2012; 24: 37-41. http://dx.doi.org/10.1007/BF03325352 